\title{
Optimal Measuring and Energy Planning of Smart Grid Considering the Battery Lifetime by Using FFA
}

\author{
Shaik Karimulla ${ }^{a}$ K. Ravi ${ }^{\mathrm{b}}$ \\ ${ }^{\mathrm{a}, \mathrm{b}}$ School of Electrical Engineering-SELECT, Vellore Institute of Technology, VIT-Vellore-632014, \\ Tamil Nadu, India. \\ ${ }^{a}$ E-Mail id: shaikkarimullah707@gmail.com \\ ${ }^{\mathrm{b}}$ Corresponding Author- K. Ravi, E-Mail id: k.ravi@vit.ac.in
}

Article History: Received: 10 November 2020; Revised 12 January 2021 Accepted: 27 January 2021; Published online: 5 April 2021

\begin{abstract}
The ceaselessly developing request for power in this world privileges a productive and dependable framework of energy sources. Disseminated energy assets such as wind-based energy and solar-based energy can remain shared inside a smart grid to source energy to the utilizers in a feasible way. In arranging to safeguard the extra dependable and conservative energy source, the battery-operated capacity system is coordinated inside the smart grid. In this objective, the operational cost of smart grid is decreased by financial planning in view of the ideal estimate of the battery-operated system and the period of battery procedure. Hence, the actual period battery procedure cost is modelled in view of the perceptiveness of release individually in the time interim. In addition, the anticipated economic planning with battery-operated measuring is improved by using the Fire-Fly algorithm (FFA). The adequacy of FFA is associated through other metaheuristic strategies in relations of execution estimation files, which remain price of power also misfortune of power supply possibility. The proposed method results show that this method diminishes the price of the grid and also achieves the optimum estimate of the battery-operating to the smart grid.
\end{abstract}

Keywords: Solar energy, Wind energy, Battery energy storage system, Fire-Fly Algorithm, Smart grid.

\section{Introduction}

Within the previous few periods, the creation is sighted an exceptional rise in its people with the resulting ensuing intemperate power-supply request, together of which is the most functioning features behind worldwide heating in addition carbon emanations. Tragically, we are immobile, stubbornly dependent on utilization of relic powers which unexpectedly are still acting as the main part in providing energy used for power production and transference framework. In any case, continual and unavoidable consumption of relic fuel capital within a long time has placed a genuine burden on the administrations and energy business visionaries to be mindful sufficient to transfer near renewal of energy through RES [1]. Conservatory gas outflow is decreased by supplanting relic energies by renewable energy and mains to a development within the mechanical segment. In any case, the discontinuous landscape of RES is obstructing the solidity of control scheme within the financial intellect of the term, consequently, proficiently measured strategies take ended up the arranging of day time to overwhelmed the problems of electrical energy disorders, frequency controls, organize safety amid the high entrance of the RES to reach the developing request of the residents at expansive [2]. Smart grids have emerged as a platform for integrating components such as fuel cell (FC), microturbine (MT), wind turbine (WT), solar photovoltaic (PV) boards, and energy storage system (ESS) inside a framework to boost interest in the efficacy network in a more methodical and reasonable framework. Smart grids can be operated in a straight forward manner, depending on the stack conditions and power showcase cost [3] [4], allowing the remaining control framework issues of soundness, unwavering quality, and request reaction to be resolved.

Since of the restricted scope of efficacy grid, the smart grid method is a supplementary aiming for power stability as related to the grid related method. Subsequently, dependable power sources like synchronous 
generators in addition to vitality storing are the significant components towards direct electrical energy and frequency move forward to the permanency of the structure [5] [6]. For a long time, ESS has been a critical component of the smart grid. The voltage and frequency control can be completed through ESS within the nonappearance synchronous generators. Furthermore, power changes initiated via the RES container are reduced in ESS. Furthermore, ESS is capable of storing vitality during the stages of large power generation and discharging it once the stack exceeds power generation size. ESS with a high vitality concentration and a long release time are used to meet the demands of commercial energy celerity and crest shaving. On the other hand, huge power mass ESS by a quick reaction ability is utilized for the electrical energy control and frequency parameter requests [7] [8]. Battery energy storing schemes are most suitable for power structure submissions due to the direction of their specialized profits and capacity towards supplying the power and energy concentration. In arranging to safeguard the unwavering quality, safety and financial reimbursements of the smart grid, discovering an ideal measure related to BESS is exceptionally necessary. Aside from an ideal battery measure, financial planning is also important for country charge plans in small towns where the electrical network is not accessible. The procedure and planning of BESS has been tended to by numerous analysts, but then the plan and estimation of its optimum measure in the direction of realizing a price effective scheme by least controlling losses is still in advance. The energy storing estimate is decided aimed at the frequency direction facilities in smart grid. The over-burdening representative of BESS is executed used for a brief time period toward control frequency, coming about in a fast reaction of the battery to overwhelm a power divergence [9]. A stack shedding conspires to determine an ideal battery estimate. The developed strategy was completed using a meta heuristic optimization procedure to expert the frequency and reduce the smart grid's working fetched [10].

A normal load and renewable source information has been measured for BESS measuring in the direction of decreasing the entire cost and increasing the financial assistance of the smart grid [11]. The impact of instability of renewable sources on BESS and planning of DER are improved through this current method. A multi objective optimization issue for the ideal area and measuring BESS is measured in [12] intended for the reason of voltage regulator of the smart grid. Total distribution system losses, aside from the BESS fixing price, are reduced, as is the speculation price of DER (Distributed energy resources). The electrical energy profiles conveyance arrangement was moved forward and the battery-operated lifetime was expanded, in this manner sparing the substitution price. The accuracy list recognized as loss of load desire is considered in [13] It makes a difference to reducing the smart grid working charge through optimizing the battery-operated estimation [14]. The financial profits of the smart grid are defended by giving power after ESS to neighbourhood loads at a lower cost among the crest stages and monitoring intemperate power generations [15]. For a successful batteryoperated measuring, the time of use duty and bidirectional energy exchange through the grid have been considered [16]. In any case, the benefit of introducing BESS is diminished by the rise in duty [17]. A mixture method containing a heuristic and expository optimization is anticipated in [18] to design the charge and release sequence of BESS in smart grid. The energetic reaction remains actualized beneath a genuine period estimating plan to preserve and adjust among the source and request within smart grid and BESS. The outcomes explain the viable support of BESS in financial planning of the smart grid. The vulnerabilities of load, in addition to renewable energy generation, are alleviated by smart grid planning in such a way that BESS provides turning saves benefit [19]. The developed discretion stage change strategy holds the turning save requirement on the way to get an adjusted trade-off between procedure cost and unwavering quality of the smart grid. The energy planning and the price decreasing strategy in an actual time power estimating atmosphere are shown in [20]. In view of the time to diverse renewable source information for the summer and winter seasons, the source stream remains facilitated in show prescient regulator basis.

The real time power estimate to play down the cost utilization through lower and higher request seasons. n a smart network environment, the estimating instrument below to fixed rate and period of utilization and actual time estimating are linked. The lifetime of the battery is a fundamental calculation in calculating the annualized fetch of BESS and the cost of operating the smart grid [21]. The period of the battery is influenced by two fundamental components, specifically, the life cycle expressing the quantity of charge and release cycles. BESS can support the profundity of release to the sum of volume utilized by BESS [22]. A modern method has been cast towards planning energy properties within smart grid in view of optimum battery-operated size [23]. 
The addition of energy storage within a smart grid raises investment costs while decreasing the framework's operating charge. Additionally, the optimum estimate of the battery-operated drags out the period of the capacity structure and it is altogether influenced by depth of discharge (DOD). In explore, smart grid is consolidated by renewable source energy and the optimum size of energy stores to make the best use of the financial advantage and reduce the operative cost [24]. Hence, the fire-fly procedure is measured to achieve the optimum dispatch which reduces the generating cost. The objective of this work is to define the battery-operated cost condition for real period investigation in view of the depth of discharge at each period interim. Furthermore, this study suggests that the battery-operated working cost in depth of discharge (DOD) period, and thus optimum DOD, entices out the lifetime of BESS [25]. The viability of the developed technique has been confirmed by relating it through additional methods anticipated within the works. The anticipated strategy is geared toward achieving lower operating costs, barring a power source failure for a brief period of time [26].

\section{Integrated grid system}

An isolated grid structure covers three sub arrangements power request, power generation and power conveyance scheme. These subsystems primarily affect the cost of the smart grid structure [27]. They remain subordinate to scheduled climate situations and the customer facilities. This segment shows the control and price representations for wind based, solar based, and vitality storing as the DERs of the power generating sub scheme, load outline of housing region as the request sub scheme and smart grid itself stands designed as per the power supply sub scheme [28]. The amalgamation of dissimilar RESs progresses the procedure proficiency and decreases the prerequisites of source capacity as associated with it. The schematic diagram of the smart grid framework covering the three systems is revealed in figure 1.

\subsection{Model of a wind turbine}

The power of a wind turbine (WT) is determined by the power as work of the hourly wind speed [12], [29]. The connection between the production power and the speed is specified through the relationship as follows.

$$
\begin{aligned}
& P_{w, h} \\
& \begin{array}{ll}
=\left\{0 P_{w, \max } * \frac{V_{h}-V_{c, i}}{V_{r t}-V_{c, i}} P_{w, \max }\right. & V_{h} \leq V_{c, i} \text { or } V_{h} \geq V_{c, o} \quad V_{c, i} \leq V_{h} \leq V_{r t} \quad V_{r t} \\
\leq V_{h} \leq V_{c, o} \quad \text { (1) } &
\end{array}
\end{aligned}
$$

The amount of power dispersed in a wind turbine during a specific day time is the control forwarded and the wind turbine's starting rate. The investment recuperation factor calculates the display esteem used for a 24-hour examination, taking into account the intriguing amount and the anticipated period of contemplation.

$$
\begin{gathered}
C_{W T}=\left(\sum_{t=1}^{T} P_{w, h}(t)\right) * I C_{W T} * C R F \\
C R F=\frac{1}{365} \times \frac{i_{r}\left(1+i_{r}\right)^{l y}}{\left(1+i_{r}\right)^{l y}-1}
\end{gathered}
$$

\subsection{Solar photo voltaic model (SPV)}

The power considered through solar based photovoltaic array is subordinate to the solar irradiation and the ambient temperature at 60 minutes. The SPV power is taken through [24], [30].

$$
P_{P V, \text { out }}=P_{P V, \text { rated }} * \frac{I}{I_{\text {ref }}} *\left[1+K_{t}\left\{\left(T_{\text {amb }}+(0.0256 * I)\right)-T_{\text {ref }}\right\}\right]
$$

The cost of power transmitted by a solar-powered photovoltaic system is secondary to the primary cost and power output, which are described in the following equation. 


$$
C_{P V}=\left(\sum_{t=1}^{T} P_{P V, \text { out }}(t)\right) * I C_{P V} * C R F
$$

\subsection{Battery energy storage (BES)}

The BESS in a smart grid is utilized to maintain a strategic distance from the least power divergence between the request and generating power [31]. The selection of various battery energy storing units, each with distinct power and energy characteristics, is based on the nature of the control required and the power conveyed. Lithium ion batteries utilized in this objective work as they remain right now basically utilized for putting away wind and solar powered vitality in the direction of its higher energy viscosity between additional battery technologies, extended lifecycle and higher productivity [32]. The increase in discharge power is caused by decreasing the size of the energy capacity and increasing the origin depth of discharge. In any case, the persistent release of high power from the vitality storage at the most extreme depth of discharge increments the charge of the energy stored towards the greatest rate [33]. Equation (6) defines the charging-discharging batteryoperated at any time period as a work of battery power. The following equations depict the life cycle of a lithium-ion battery-powered device as determined by [34] the cost function of battery capacity during charge and discharge events.

$$
\begin{gathered}
C_{\text {BATT }}(t)=\frac{C_{\text {batt,cap }} * P_{\text {batt }}(t) * \Delta t}{E_{\text {batt }, t} * l_{C}\left(D O D_{\text {batt }}(t) * \eta_{\text {batt }}{ }^{2}\right.} \\
l_{c}\left(D O D_{\text {batt }}(t)\right)=694 *\left(D O D_{\text {batt }}(t)\right)^{-0.795} \\
D O D_{\text {batt }}(t)=1-S O C_{\text {batt }}(t) \\
\operatorname{SOC}_{\text {bat }}(t+1)=S O C_{\text {batt }}(t)-\frac{P_{\text {batt }, c h}(t) * \Delta t * \eta_{\text {batt }}^{c h}}{E_{\text {batt }, t}}-\frac{P_{\text {batt, dch }}(t) * \Delta t}{E_{\text {batt }, t} * \eta_{\text {batt }}^{\text {dch }}}
\end{gathered}
$$

\section{Management of power strategy}

The management of power strategy methodology of the smart grid has a direct effect on the operational behaviour of the arrangement, regardless of whether it is connected to the grid or not. However, in the separated method, the power generated after the conveyed properties must meet the load request for a safe and dependable procedure, or else the structure will encounter load coming off, which can increase the cost in span of power misfortunes [35].The additional energy afterwards charging is disseminated into dump load to maintain a strategic overpricing of batteries [36]. In this way, a proficient power administration methodology is essential to expedite the power at the least price to dependably help the load in view of the specialized constrictions of the smart grid and for the management of power strategy for financial planning [37]. Renewable energy sources can supply adequate vitality to reach the load request and the battery is charged through overabundance of energy [38]. This situation is analogous to the overhead situation, with the exception that the battery-operated system is fully charged, and an additional source generated through renewable energy is distributed as dump load. RE assets can not fulfil the specified load of the structure [39]. The procedure will choose the battery dependent on the specified load and price amassed in dual disseminated sources. The RES generation helps the specified load and depth of discharge of battery capacity is low [40].

\subsection{Tariff of electricity}

The cost of power is considered as a marker of the financial productivity of a smart grid taken from the below equation.

$$
\text { Cost of Electricity }=\frac{C_{P V}+C_{W T}+\sum_{t=1}^{T}\left(C_{B A T T}\right)}{\sum_{i=0}^{n} P_{L}}
$$


The cost of electricity is divided between the power generation resources and load intended for the dayand-night (24) investigation, the energy storage (CBATT), wind turbine (CWT), and solar photovoltaic (CPV), and the overall load of the day.

\subsection{Reliability study}

The reliability of smart grid is restrained by the measurable constraint to the cost of power supply. The reliability constraint means the possibility over the period skyline after the generation comes up short to fulfil the request. This dereliction is either due to the inappropriate planning of the disseminated energy assets, quick droplet in renewable energy or else increment in power request loss of power supply probability (LPSP) can be considered through either utilizing period arrangement information or in deciding energy aggregate impact over the entire load. A new method has been utilized in this objective, as appears in the following equations.

$$
L P S P=\frac{\sum_{t=1}^{T}\left(P_{L}-P_{P V, \text { out }}-P_{w, h}-P_{b a t t, d c h}\right)}{\sum_{i=0}^{n} P_{L}}
$$

\subsection{Energy storage system constraints}

The battery-operated charging and discharging energy are communicated in Equation (12). When Pbatt is negative, the battery is charging; when Pbatt is positive, the battery discharges.

$E_{\text {batt }}(t+1)$

$=\left\{E_{\text {batt }}(t)-\frac{P_{\text {batt }, d c h}(t) * \Delta t}{\eta_{\text {batt }}^{\text {dch }}} E_{\text {batt }}(t)-P_{\text {batt }, c h}(t) * \Delta t * \eta_{\text {batt }}^{c h}\left(P_{\text {batt }}(t)>0\right)\left(P_{\text {batt }}(t)<0\right)\right.$

$$
\begin{aligned}
& P_{\text {batt }}^{\min } \leq P_{\text {batt }}(t) \leq P_{\text {batt }}^{\max } \\
& 0 \leq P_{\text {batt,dch }}(t) \leq P_{\text {batt }} * \mu_{\text {batt }, s t} \\
& -P_{\text {batt }} *\left(1-\mu_{\text {batt }, s t}\right) \leq P_{\text {batt }, c h}(t) \leq 0 \\
& E_{\text {batt }}^{\min } \leq E_{\text {batt }}(t) \leq E_{\text {batt }}^{\max }
\end{aligned}
$$

- $\quad \mu b a t t, s t$ is the operating status of battery charge and discharge.

- $\quad P_{b a t t}^{\min }$ and $P_{b a t t}^{\max }$ are maximum and minimum power battery charge and discharge.

- $E_{\text {batt }}^{\min }$ and $E_{\text {batt }}^{\max }$ are minimum and maximum battery capacity at each interval.

\subsection{Power stability}

The essential parameter within the power system stability of request and supply is considered from the below equation.

$$
P_{P V, \text { out }}(t)+P_{w, h}(t)+P_{\text {batt }}(t)-P_{L}(t)=0
$$


Table 1. Wind turbine parameters

\begin{tabular}{cc}
\hline $\begin{array}{c}\text { Parameters of } \\
\text { components }\end{array}$ & Value \\
\hline Initial capital cost & $2000(\$ / \mathrm{kW})$ \\
\hline Rated power & $37(\mathrm{~kW})$ \\
\hline Rated speed & $7(\mathrm{~m} / \mathrm{s})$ \\
\hline Cut out speed & $16(\mathrm{~m} / \mathrm{s})$ \\
\hline Cut in speed & $2.5(\mathrm{~m} / \mathrm{s})$ \\
\hline Lifetime & $10($ years $)$ \\
\hline
\end{tabular}

Table 2. Solar PV parameters

\begin{tabular}{cc}
\hline $\begin{array}{c}\text { Parameters of } \\
\text { components }\end{array}$ & Value \\
\hline Initial capital cost & $3000(\$ / \mathrm{kW})$ \\
\hline Rated power & $68(\mathrm{~kW})$ \\
\hline Lifetime & $10($ years $)$ \\
\hline
\end{tabular}

Table 3. Energy storage parameters.

\begin{tabular}{cc}
\hline $\begin{array}{c}\text { Parameters of } \\
\text { components }\end{array}$ & Value \\
\hline Initial capital cost & $625(\$ / \mathrm{kWh})$ \\
\hline Initial SOC & $75(\%)$ \\
\hline Round trip efficiency & $90(\%)$ \\
\hline SOC $_{\text {batt }}{ }^{\max }$ & $90(\%)$ \\
\hline SOC $_{\text {batt }}{ }^{\mathrm{min}}$ & $15(\%)$ \\
\hline Maintenance cost $^{\max }$ & $25(\$ / \mathrm{kWh}) /$ year \\
\hline $\mathrm{P}_{\text {batt }}{ }^{\min }$ & $25(\mathrm{~kW})$ \\
\hline $\mathrm{P}_{\text {batt }}{ }^{2}$ & $10(\mathrm{~kW})$ \\
\hline Lifetime & $3(\mathrm{years})$ \\
\hline
\end{tabular}

\section{Proposed method}

The planned strategy computes the ideal battery-operated measure and completes economic planning of the conveyed generators for each load request each 60 minutes. The economic planning is dependent on the power management methodologies investigated and is comparable to the conservative strategy when there is an excess of energy by the RES than that required by loads, as per power management techniques. In any case, after the load power is more prominent than RES generation, the new algorithm determines production of the power after the energy loading. The algorithm is based on the depth of release of the energy storing, which influences the operational cost of capacity peruses DOD esteem at the beginning of the interim, after that, changes cost purpose. The developed optimization algorithm reports the optimum power on or after energy storage, based on the price conditions of individual dispersed power properties and load request at the specific 60-minute interval. In this configuration, the battery DOD is higher, which may be the cause of the power source mishap amid the 60-minute period, when the battery is required to expedite control. The batteryoperated SOC is calculated at the end of each 60-minute period, after which the algorithm decides whether to charge or discharge the battery. The battery-operated optimum measure is premeditated for the characterized techniques so that the price is least for planning of power sources, which can decrease the general cost of a smart grid. 


\subsection{Fire-Fly Algorithm-FFA (Procedure)}

The fire-fly algorithm (FA) investigates the communal behaviour of flies also is proportional to additional meta-heuristic procedures. The calculation was initially created by Yang [41], founded on three fundamental thoughts,

1) The fire-flies pull in their coupling partners.

2) The positive fire-fly gets pulled in in the direction of brighter fireflies.

3) If the firefly cannot discover brighter fireflies, at that point it'll move arbitrarily within the looking space.

Similar additional optimization methods such as PSO and harmony search algorithm (HSA) artificial bee colony (ABC), are created on the populace of exploration space, FFA is additionally a populace grounded optimization algorithm. In any case, FFA is recognized after the other optimization methods through altering the constraints, like having small reliance on calculation also suitably recognizing exploration space.

\subsection{Division between fireflies}

The separate among two coupling fire-flies in the exploration space is planned as direction procedure made in Cartesian system among $\mathrm{i}^{\text {th }}$ and $\mathrm{j}^{\text {th }}$ fire-fly considered through the equation

$$
r_{i j}=\left|Y_{i}-Y_{j}\right|=\sqrt{\sum_{D=1}^{S}\left(Y_{i, D}-Y_{j, D}\right)^{2}}
$$

here $r$ is separate among two fire-flies, $S$ is measurement of control direction, $Y_{i, D} / Y_{j}$, D are the $D_{\text {th }}$ dimensions of $\mathrm{Yi} / \mathrm{Yj}$ fire-flies correspondingly.

\subsection{Fascination among fire-fly}

The fascination of the fire-flies diminishes when two coupling fire-flies transfers in inverse path and the division among them increments. The fascination of flies can be characterized in the after appearance by the following equation.

$$
\beta(r)=\beta_{0} \times \exp \left(-\gamma r^{m}\right) ; m \geq 1
$$

Here $\beta(r)$ and $\beta_{0}$ shows to the engaging quality at which fire-flies are at length $\mathrm{r}$ and 0 .

$\gamma$ is coefficient of light ingested through fire-flies and $m$ is the quantity of fire-flies.

\subsection{Development of the fireflies}

The fireflies transfer in the direction of brighter fire-flies. The development of the two fire-flies, $j^{\text {th }}$ firefly (low concentrated) in the direction of the $i^{\text {th }}$ fire-fly (high concentrated) is specified by numerical equation.

$$
\begin{aligned}
& Y_{j}(t)=Y_{j}+\beta_{0} \times \exp \left(-\gamma r^{m}\right) \times\left(Y_{i}-Y_{j}\right)+V_{j} \\
& V_{j}=\delta(\text { rand }-0.5)
\end{aligned}
$$

The primary expression of the Equation (20) shows the location of $\mathrm{j}^{\text {th }}$ fire-fly. The secondary expressions denote concentrated of brightness through the $\mathrm{j}^{\text {th }}$ fire-fly is drawn towards $\mathrm{i}^{\text {th }}$ firefly. In any case, final expression $v_{j}$ expresses to the development of $j^{\text {th }}$ fire-fly within the whole exploration space after it cannot discovery fire-flies through additional concentrated. The accidental limit $\delta$ could be a steady esteem within the run of $0-0.5$. 


\section{Results}

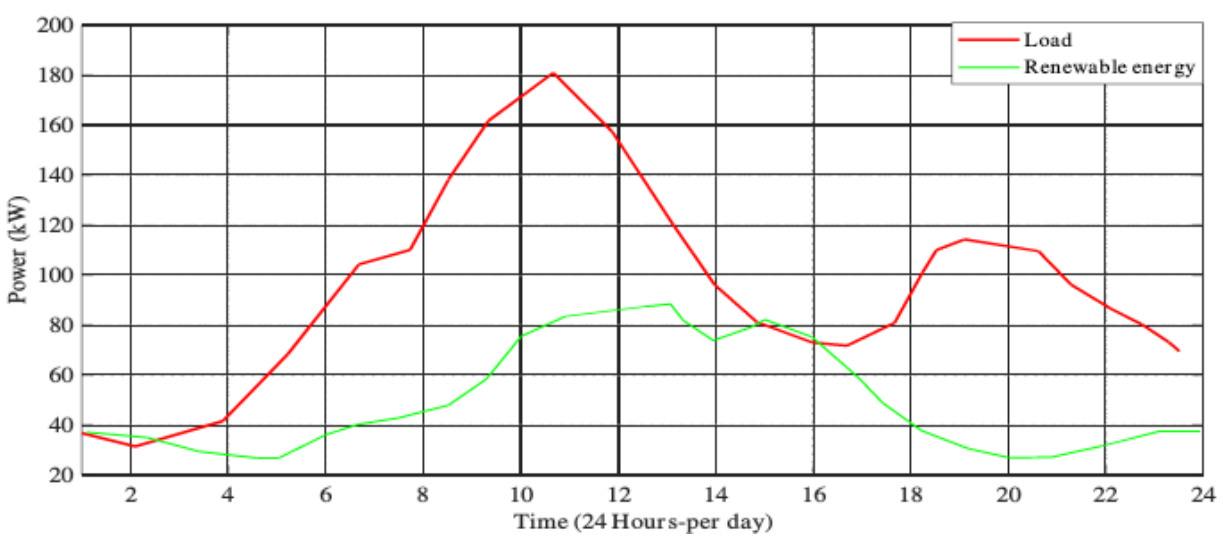

Figure 4. Load and renewable energy

The figure 4 above shows a typical load profile of a small private zone where the top load has been considered in this section. The smart grid load outline and RES graphs are shown. The load request at maximum occurrences is more than the collective of wind-based and solar-based power generations.

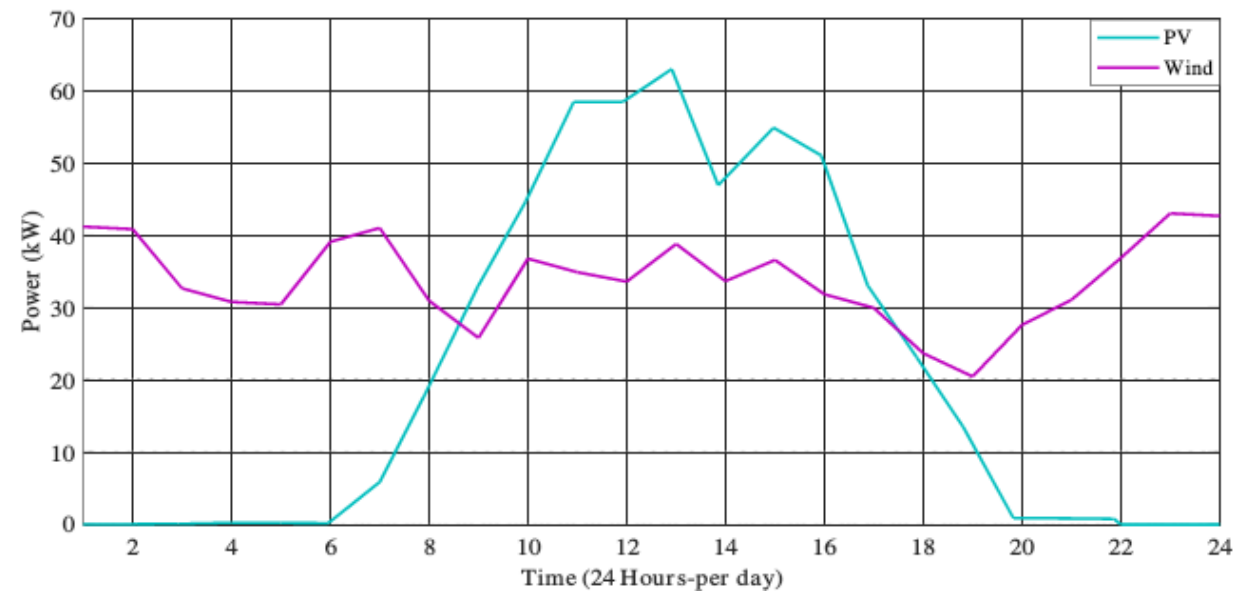

Figure 5. Photovoltaic and wind energy

The above figure 5 shows the generation of two renewable energy sources per day. One is wind and the another is solar photovoltaic system (SPV). Wind energy shows continuous generation of power during the day and will be constant in generation according to wind speed, whereas solar photovoltaic (SPV) generation is only during the day with an approximate time of 6am to 7pm (6-19 in 24-hours) and the maximum generation will be in peak time such as 11 am to $3 \mathrm{pm}$ (11-15 in 24 hours).

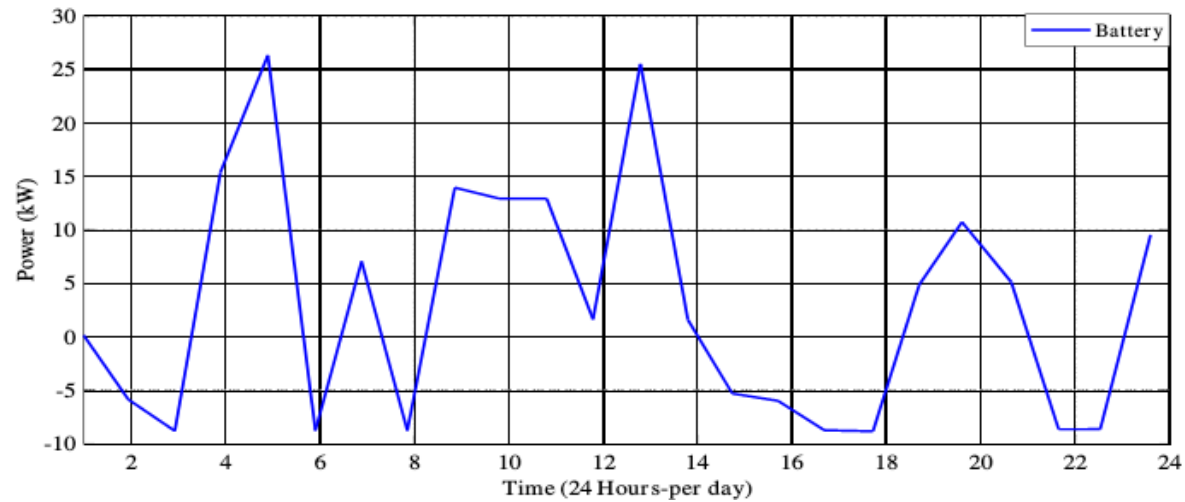

Figure 6. Battery charging and discharging analysis 
The above figure 6 shows the analysis of battery charging and discharging in a day ( $24 \mathrm{hrs})$. In this the consideration is positive and negative, which means discharging and storing. The negative side means the battery is in storing or charging mode whereas the positive side is discharging of power. From the above graph it shows the maximum time is to discharge only because of load demand request. Typically, to keep a strategic distance from the total release of the battery-powered storing in one intermission, the battery can be used throughout critical time periods.

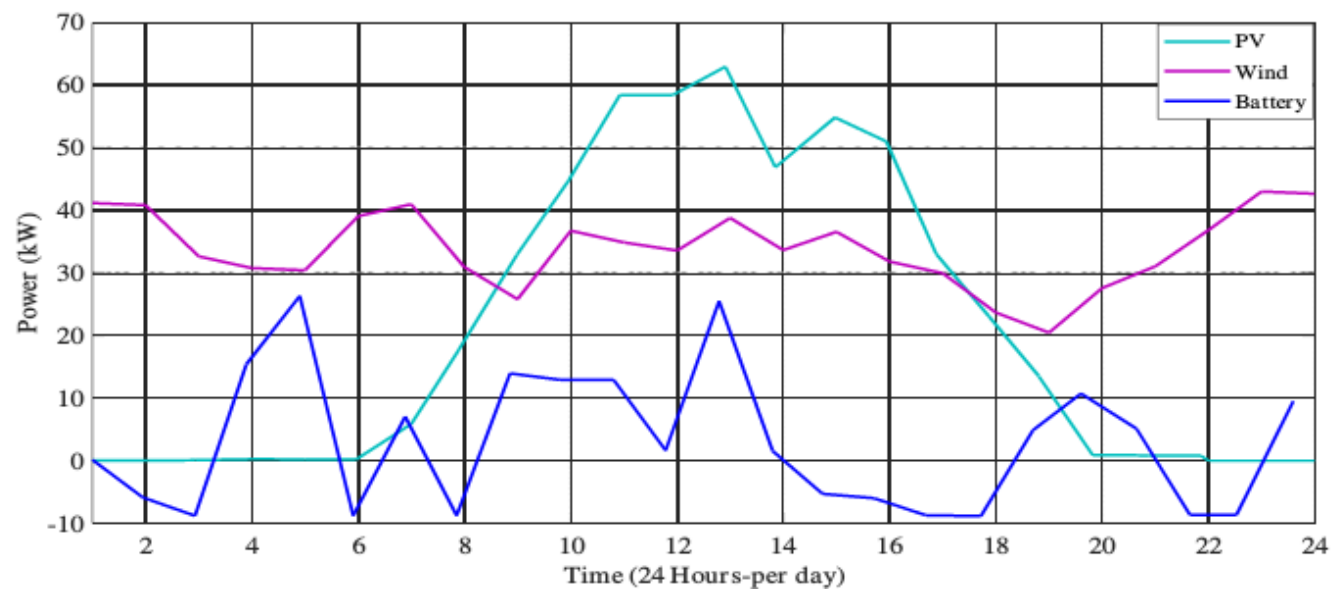

Figure 7. Renewable energy sources with battery

The above figure 7 shows the graphs with all three types of energy sources, whereas renewable energy can't fulfil the load demand, so with the help of different sources like solar, wind and with battery systems it can satisfy the request of load demand.

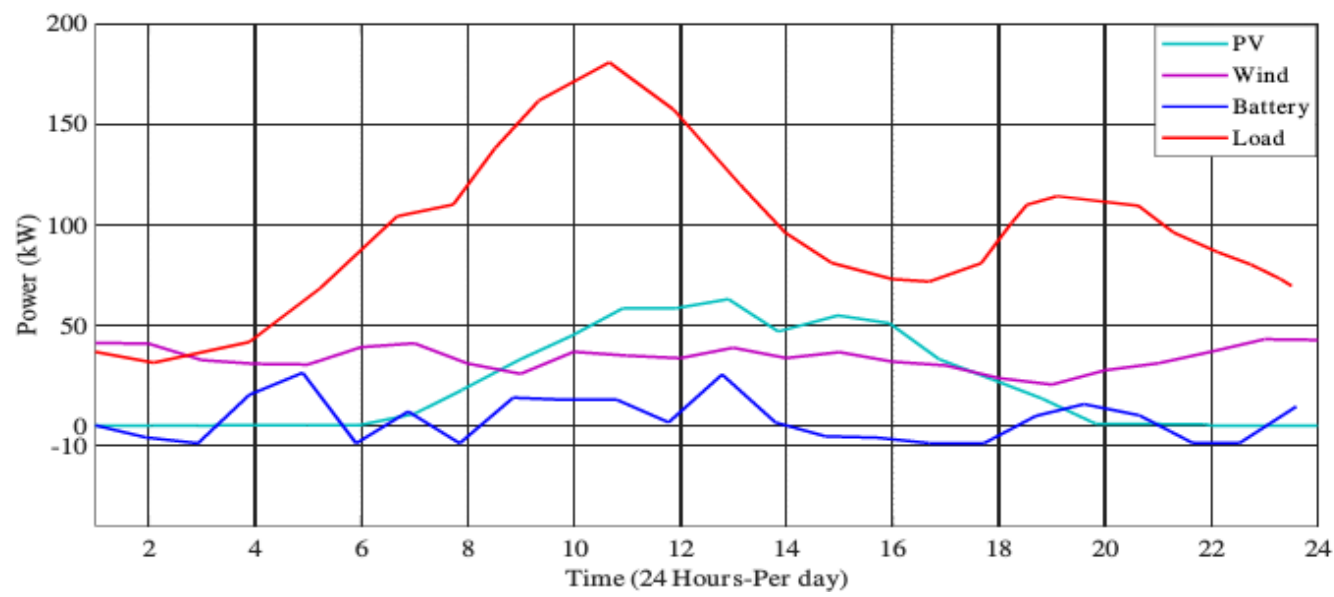

Figure 8. Operation with all sources with smart grid

The above figure 8 shows the generation of power with the load in This shows that the load demand is greater, so consider solar and wind power, as well as additional batteries, to meet the requirement. The load profile is considered to be around $165 \mathrm{Kw}$. For efficiency and low cost, the entire operation is carried out in a smart grid. This helps to utilize all resources with less loss. The distribution will be in an easy manner in a smart grid system. 


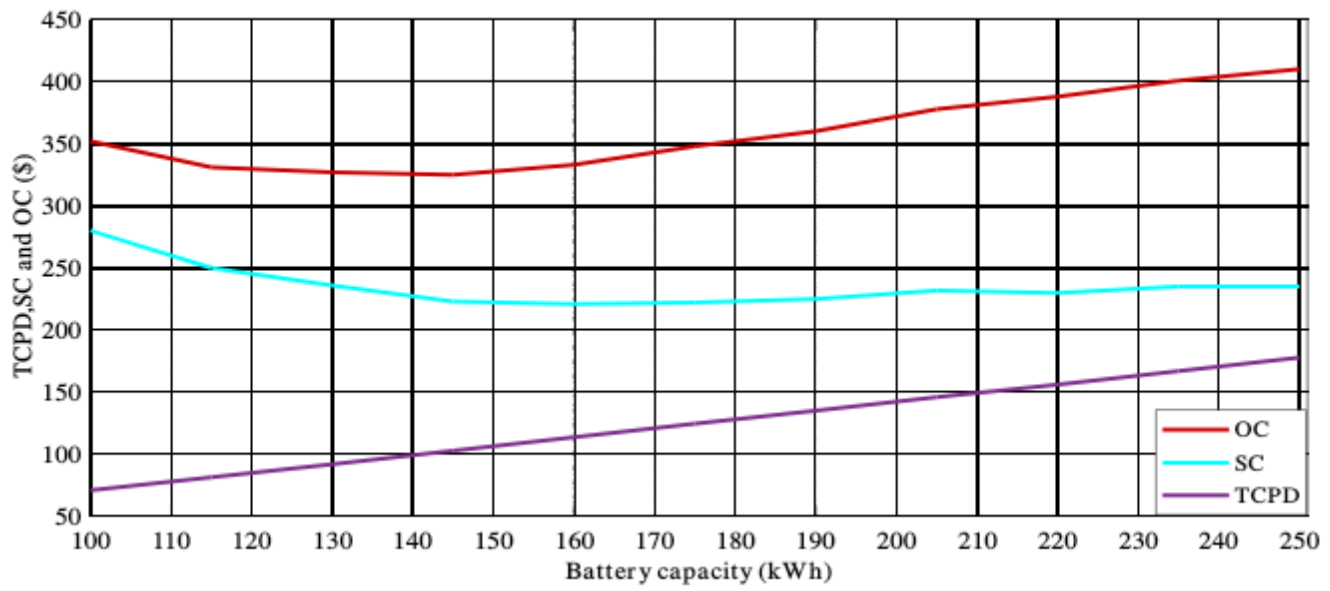

Figure 9. Operating cost and scheduling cost

The above figure 9 shows the operating cost and scheduling cost of the battery whereas battery capacity is considered to be between 100- $250 \mathrm{kWh}$. The operating cost will rise as battery capacity increases because the starting OC is less than $100 \mathrm{kWh}$, and it rises as battery capacity increases. After a certain point in battery size capacity, the scheduling cost (SC) decreases and becomes constant. It means SC is more for smaller size capacities. And decreases for higher size battery capacities. Total cost per day (TCPD) will continue to rise as battery capacity increases; TCPD is directly proportional to battery capacity.

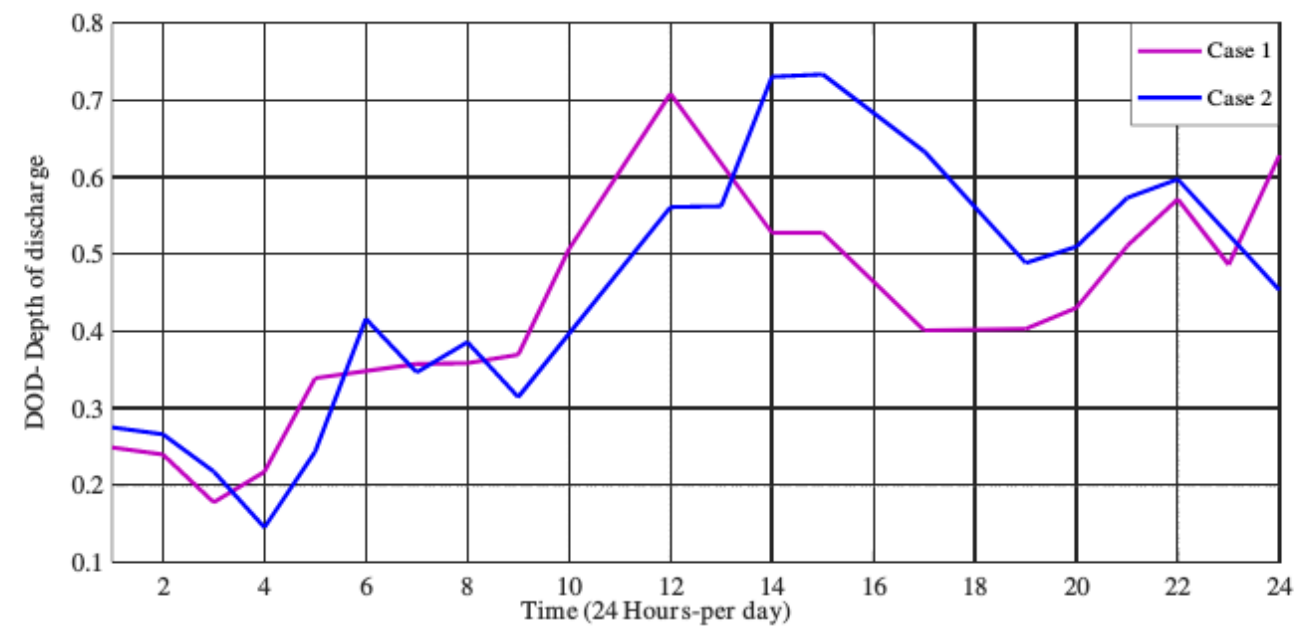

Figure 10. Status of battery of depth of discharge in case 1 and 2

The above figure 10 shows the depth of discharge (DOD) of the battery in two cases with and without adding 100kWh. The depth of discharge is increased in Case 2 by adding, and equal it increases the batteryoperated and power while charging the battery; the battery should release in these occurrences in the direction of evade load detaching. The DOD values these occurrences increases and battery-powered releases regardless of the higher cost. The basic $24 \mathrm{hrs}$ are measured as individual hours after renewable vitality sources working together can not reach the load request. Despite the higher cost of battery capacity, it releases power in the direction of satisfying load demand, resulting in the battery not being completely drained and avoiding profound releases, which extends the battery lifecycle time. 


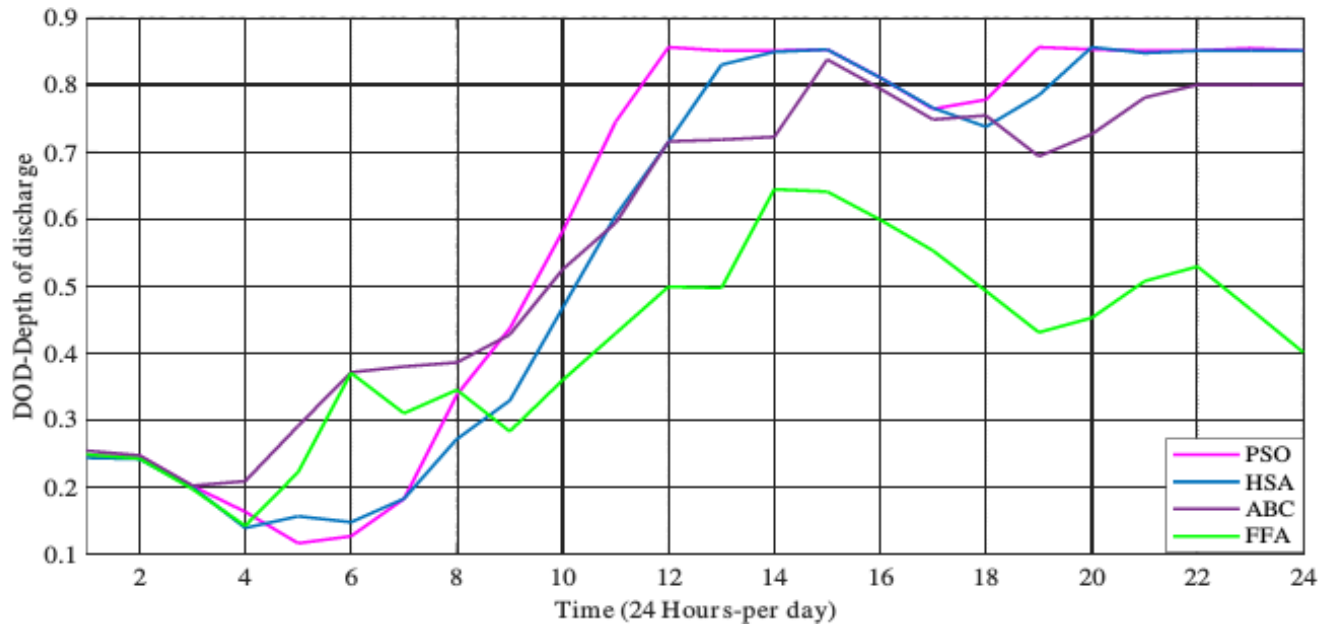

Figure 11. Comparison status of depth of discharge with other algorithms

The above figure 11 shows the comparison status for depth of discharge with different algorithms such as particle swarm optimization (PSO), Harmony search algorithm (HSA), and Artificial bee colony (ABC) with the proposed method Firefly algorithm (FFA). The proposed method is useful to resolve the economic load dispatch and battery-operated size. The life expectancy of the battery is additionally expanded when optimum the estimate is chosen for economic scheduling saving cost of supplanting BESS.

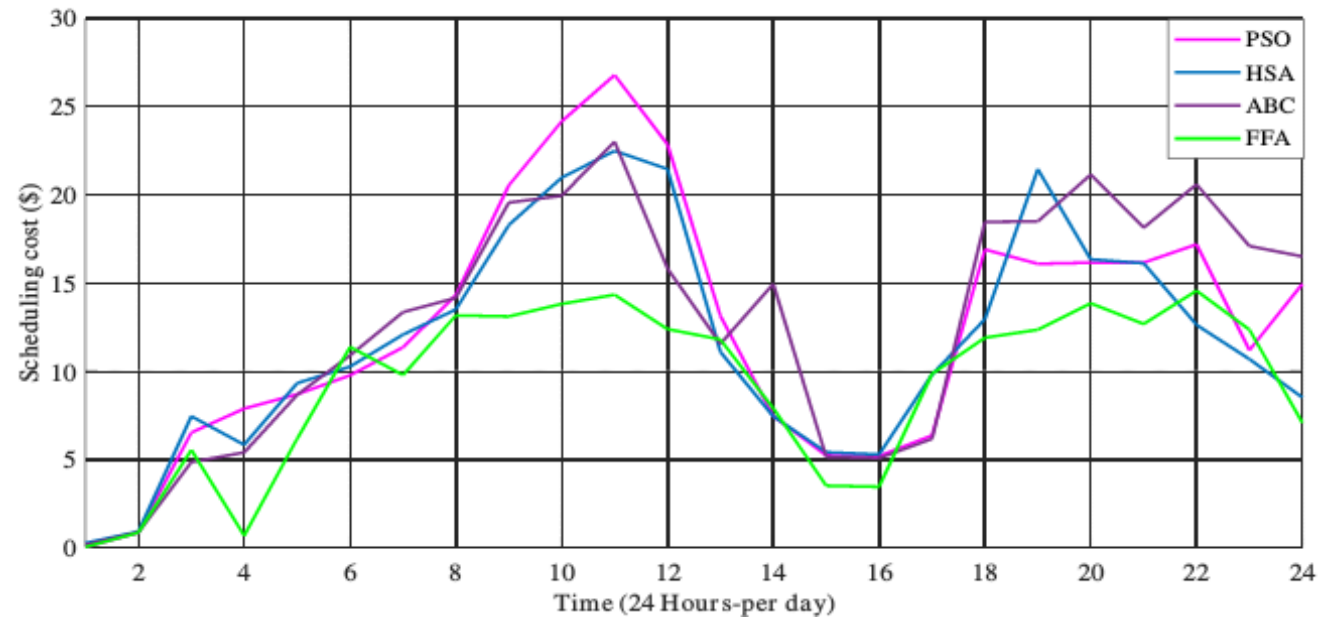

Figure 12. Comparison status of scheduling cost with other algorithms

The above figure 12 shows the comparison of scheduling cost with other algorithms such as particle swarm optimization (PSO), Harmony search algorithm (HSA), and Artificial bee colony (ABC) with the proposed method Firefly algorithm (FFA). The proposed method results show the firefly algorithm (FFA) having less scheduling cost with other algorithms.

\section{Conclusion}

As more vitality sources are anticipated to be directed toward operating renewable sources, financial and battery-powered sizing perspectives of energy storing within the smart grid should be considered to ensure a consistent benefit. The important feature of a smart grid is its ability to use low-cost renewable energy sources. The unique quality of the developed strategy is to charge the battery after the depth of discharge is higher. Therefore, the battery-operated isn't drained during the basic 60 minutes. Fire-fly optimization calculation is executed to unravel the financial celerity and the battery measuring issue. The proposed method is useful to 
solve the economic load dispatch and battery-operated size. The discharge comparison results show that the battery releasing cost of FFA is the least of all the other methods, and the results show that FFA is capable of constraining battery DOD near a short esteem towards lowering the battery operative price. The planning cost for every 60 minutes in 24 hours investigation with a battery-operating estimate of $145 \mathrm{kWh}$ is associated with other algorithms. The scheduling cost results show the comparison with other algorithms which are lower and which diminish the normal working cost.

\section{References}

[1]. Jamshidi M, Askarzadeh A. Techno-economic analysis and size optimization of an off- grid hybrid photovoltaic, fuel cell and diesel generator system. Sustainable Cities and Society. 2019 Jan 1;44:31020 .

[2]. Hossain MS, Madlool NA, Rahim NA, Selvaraj J, Pandey AK, Khan AF. Role of smart grid in renewable energy: An overview. Renewable and Sustainable Energy Reviews. $2016 \mathrm{Jul}$ 1; 60:1168-84.

[3]. Alsaidan I, Khodaei A, Gao W. A comprehensive battery energy storage optimal sizing model for microgrid applications. IEEE Transactions on Power Systems. 2017 Nov 3;33(4):3968-80.

[4]. Robert FC, Sisodia GS, Gopalan S. A critical review on the utilization of storage and demand response for the implementation of renewable energy microgrids. Sustainable cities and society. $2018 \mathrm{Jul} \mathrm{1 \text {; }}$ 40:735-45.

[5]. Carta JA, Velázquez S. A new probabilistic method to estimate the long-term wind speed characteristics at a potential wind energy conversion site. Energy. 2011 May 1;36(5):2671-85.

[6]. Castronuovo ED, Lopes JP. On the optimization of the daily operation of a wind-hydro power plant. IEEE Transactions on Power Systems. 2004 Aug 2;19(3):1599-606.

[7]. Sufyan M, Abd Rahim N, Tan C, Muhammad MA, Sheikh Raihan SR. Optimal sizing and energy scheduling of isolated microgrid considering the battery lifetime degradation. PloS one. 2019 Feb 14;14(2):e0211642.

[8]. Fu Q, Hamidi A, Nasiri A, Bhavaraju V, Krstic SB, Theisen P. The Role of Energy Storage in a Microgrid Concept: Examining the opportunities and promise of microgrids. IEEE Electrification Magazine. 2013 Dec;1(2):21-9.

[9]. Aghamohammadi MR, Abdolahinia H. A new approach for optimal sizing of battery energy storage system for primary frequency control of islanded microgrid. International Journal of Electrical Power \& Energy Systems. 2014 Jan 1;54:325-33.

[10]. Kerdphol T, Qudaih Y, Mitani Y. Battery energy storage system size optimization in microgrid using particle swarm optimization. In IEEE PES Innovative Smart Grid Technologies, Europe 2014 Oct 12 (pp. 1-6). IEEE.

[11]. Khorramdel H, Aghaei J, Khorramdel B, Siano P. Optimal battery sizing in microgrids using probabilistic unit commitment. IEEE Transactions on Industrial Informatics. 2015 Dec 17;12(2):83443.

[12]. Mehmood KK, Khan SU, Lee SJ, Haider ZM, Rafique MK, Kim CH. Optimal sizing and allocation of battery energy storage systems with wind and solar power DGs in a distribution network for voltage regulation considering the lifespan of batteries. IET Renewable Power Generation. 2017 May 25;11(10):1305-15.

[13]. Bahramirad S, Reder W, Khodaei A. Reliability-constrained optimal sizing of energy storage system in a microgrid. IEEE Transactions on Smart Grid. 2012 Dec 10;3(4):2056-62.

[14]. Rokni SG, Radmehr M, Zakariazadeh A. Optimum energy resource scheduling in a microgrid using a distributed algorithm framework. Sustainable cities and society. 2018 Feb 1; 37:222-31.

[15]. Li Y, Yang Z, Li G, Zhao D, Tian W. Optimal scheduling of an isolated microgrid with battery storage considering load and renewable generation uncertainties. IEEE Transactions on Industrial Electronics. 2018 Jun 1;66(2):1565-75.

[16]. Carpinelli G, Mottola F, Proto D. Probabilistic sizing of battery energy storage when time-of-use pricing is applied. Electric Power Systems Research. 2016 Dec 1;141:73-83.

[17]. Nguyen TA, Crow ML, Elmore AC. Optimal sizing of a vanadium redox battery system for microgrid systems. IEEE transactions on sustainable energy. 2015 Apr 3;6(3):729-37. 
[18]. Li Y, Yang Z, Li G, Zhao D, Tian W. Optimal scheduling of an isolated microgrid with battery storage considering load and renewable generation uncertainties. IEEE Transactions on Industrial Electronics. 2018 Jun 1;66(2):1565-75.

[19]. Alharbi H, Bhattacharya K. Stochastic optimal planning of battery energy storage systems for isolated microgrids. IEEE Transactions on Sustainable Energy. 2017 Jul 11;9(1):211-27.

[20]. Nojavan S, Zare K, Mohammadi-Ivatloo B. Risk-based framework for supplying electricity from renewable generation-owning retailers to price-sensitive customers using information gap decision theory. International Journal of Electrical Power \& Energy Systems. 2017 Dec 1;93:156-70.

[21]. Mbungu NT, Bansal RC, Naidoo R, Miranda V, Bipath M. An optimal energy management system for a commercial building with renewable energy generation under real-time electricity prices. Sustainable cities and society. 2018 Aug 1; 41:392-404.

[22]. Sharma S, Bhattacharjee S, Bhattacharya A. Grey wolf optimisation for optimal sizing of battery energy storage device to minimise operation cost of microgrid. IET Generation, Transmission \& Distribution. 2016 Feb 18;10(3):625-37.

[23]. Nojavan S, Zare K. Interval optimization-based performance of photovoltaic/wind/FC/electrolyzer/electric vehicles in energy price determination for customers by electricity retailer. Solar Energy. 2018 Sep 1;171:580-92.

[24]. Borhanazad H, Mekhilef S, Ganapathy VG, Modiri-Delshad M, Mirtaheri A. Optimization of microgrid system using MOPSO. Renewable Energy. 2014 Nov 1;71:295-306.

[25]. Sukumar S, Mokhlis H, Mekhilef S, Naidu K, Karimi M. Mix-mode energy management strategy and battery sizing for economic operation of grid-tied microgrid. Energy. 2017 Jan 1;118:1322-33.

[26]. Fossati JP, Galarza A, Martín-Villate A, Fontan L. A method for optimal sizing energy storage systems for microgrids. Renewable Energy. 2015 May 1;77:539-49.

[27]. Reddy KS, Kumar M, Mallick TK, Sharon H, Lokeswaran S. A review of Integration, Control, Communication and Metering (ICCM) of renewable energy based smart grid. Renewable and Sustainable Energy Reviews. 2014 Oct 1;38:180-92.

[28]. Mwasilu F, Justo JJ, Kim EK, Do TD, Jung JW. Electric vehicles and smart grid interaction: A review on vehicle to grid and renewable energy sources integration. Renewable and sustainable energy reviews. 2014 Jun 1;34:501-16.

[29]. Ju C, Wang P. Energy management system for microgrids including batteries with degradation costs. In2016 IEEE International Conference on Power System Technology (POWERCON) 2016 Sep (pp. 1 6). IEEE.

[30]. Han S, Han S, Aki H. A practical battery wear model for electric vehicle charging applications. Applied Energy. 2014 Jan 1;113:1100-8.

[31]. Zhou C, Qian K, Allan M, Zhou W. Modeling of the cost of EV battery wear due to V2G application in power systems. IEEE Transactions on Energy Conversion. 2011 Jul 21;26(4):1041-50.

[32]. Amamra SA, Ahmed H, El-Sehiemy RA. Firefly algorithm optimized robust protection scheme for DC microgrid. Electric Power Components and Systems. 2017 Jun 15;45(10):1141-51.

[33]. Chen SX, Gooi HB, Wang M. Sizing of energy storage for microgrids. IEEE Transactions on Smart Grid. 2011 Aug 11;3(1):142-51.

[34]. Ismail MS, Moghavvemi M, Mahlia TM. Techno-economic analysis of an optimized photovoltaic and diesel generator hybrid power system for remote houses in a tropical climate. Energy conversion and management. 2013 May 1;69:163-73.

[35]. Li Z, Zang C, Zeng P, Yu H, Li S. Agent-based distributed and economic automatic generation control for droop-controlled AC microgrids. IET Generation, Transmission \& Distribution. 2016 Nov 4;10(14):3622-30.

[36]. Chaurasia GS, Singh AK, Agrawal S, Sharma NK. A meta-heuristic firefly algorithm based smart control strategy and analysis of a grid connected hybrid photovoltaic/wind distributed generation system. Solar Energy. 2017 Jul 1;150:265-74.

[37]. Hesaroor K, Das D. Optimal sizing of energy storage system in islanded microgrid using incremental cost approach. Journal of Energy Storage. 2019 Aug 1;24:100768. 
[38]. Priyadarshi N, Sharma AK, Azam F. A hybrid firefly-asymmetrical fuzzy logic controller based MPPT for PV-wind-fuel grid integration. International Journal of Renewable Energy Research (IJRER). 2017 Dec 30;7(4):1546-60.

[39]. Natsheh EM, Albarbar A, Yazdani J. Modeling and control for smart grid integration of solar/wind energy conversion system. In2011 2nd IEEE PES International Conference and Exhibition on Innovative Smart Grid Technologies 2011 Dec 5 (pp. 1-8). IEEE.

[40]. Su W, Wang J, Roh J. Stochastic energy scheduling in microgrids with intermittent renewable energy resources. IEEE Transactions on Smart grid. 2013 Nov 12;5(4):1876-83.

[41]. Yang XS. Nature-inspired metaheuristic algorithms. Luniver press; 2010. 